\title{
VATER association: report of a case with three unreported malformations
}

\author{
M DUSMET*, F FÊTE†, A CRUSI†, AND J N COX* \\ Departments of Pathology*, Pediatrics, and Human Geneticst, University of Geneva, Geneva, Switzerland.
}

SUMMARY The VATER association is the sporadic non-random association of Vertebral anomalies, $A$ nal atresia, Tracheo-oesophageal fistula with Esophageal atresia, Renal defects, and Radial limb dysplasia. Cardiac defects are common, as are other limb malformations. The present report describes a premature infant with most of the known major and minor defects of the association as well as agenesis of the bladder and penis and an askeletal rudimentary tail. The latter have not previously been described.

The VATER association was first reported by Quan and Smith in $1972^{1}$ who noted the non-random association of Vertebral defects, $A$ nal atresia, Tracheo-oesophageal fistula with Esophageal atresia, Renal defects, and Radial limb dysplasia. Temtamy and Miller ${ }^{2}$ used the acronym VATERS the $\mathrm{V}$ of which represents both vertebral defects and the often present ventricular septal defect, the $S$ standing for single umbilical artery. The acronym VACTERL has also been used $(\mathrm{C}=$ cardiac defects, $\mathrm{L}=$ limb defects). ${ }^{3}$ Weaver et $a l^{4}$ have recently reported 46 cases and reviewed a further 186 published cases.

We have examined a 31 week old male infant who presented with an unusual concurrence of the major and minor defects reported in the VATER association as well as three previously unreported defects, namely agenesis of both bladder and penis and a vestigial askeletal tail.

\section{Case report}

A 32 year old para 2, gravida 3 Thai woman had an uneventful pregnancy up to the 29th week when she began to have slight vaginal spotting. The parents' family and personal histories were unremarkable (47 year old Swiss father); in particular there was no maternal history of hypertension or diabetes. The only medication taken during the pregnancy were multivitamin preparations. Ultrasound examina-

Received for publication 3 October 1986

Revised version accepted for publication 19 November 1986. tions at eight and 29 weeks were considered normal. There was no acute illness during the pregnancy. At 31 weeks two days, she was admitted with complete dilatation and 45 minutes later gave birth extremely rapidly to a male infant who cried weakly and had gasping respiratory movements. Death occurred 30 minutes later and necropsy was performed within 10 hours.

On external examination the infant weighed $1360 \mathrm{~g}$ (30th centile) with a crown-heel length of $39 \mathrm{~cm}$ (25th centile). The following malformations were noted: bilateral cleft lip with cleft palate; broad, flat nose; bilateral epicanthic folds; dysplastic, low set ears; redundant loose skin at the back of the neck; dorsolumbar scoliosis; absence of penis with rudimentary scrotum; imperforate anus; a $5 \mathrm{~mm}$ sacral caudal skin appendix; and right 'lobster claw' foot (fig 1).

Pathological and radiological examination showed the following malformations:

Respiratory: distal tracheo-oesophageal fistula with partial proximal oesophageal atresia; annular tracheal cartilage rings proximally and incomplete cartilage rings distally with partial stenosis (fig 2a); immature hypoplastic lungs (slight aspiration) with a normal diaphragm.

Digestive: microscopic foci of heterotopic intestinal mucosa in the proximal oesophageal mucosa (fig $2 \mathrm{~b}$ ); duodenal cysts of the mucosa; anal agenesis with a blind, dilated, distal, sigmoid colon at the pelvic brim.

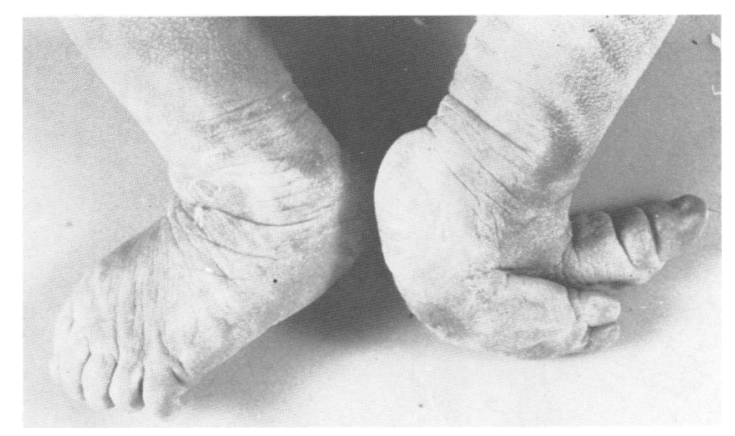

FIG 1 'Lobster-claw' malformation of the right foot associating a pes equinovarus with the absence of two digits and partial postaxial syndactyly of two others. 
Urogenital: bilateral renal dysplasia (fig 3); there was a microscopic remnant on the right side in serial sections of the retroperitoneal tissue; the left kidney was of normal size with a blind ureter (distal extremity at pelvic brim); agenesis of the bladder and urethra; normal bilateral intra-abdominal testes.
Cardiovascular: single umbilical artery (right) with:out cardiac malformations (persistent ductus arter⿳⺈? iosus).

Radiology: supernumerary right hemivertebra be등 tween $\mathrm{T} 1$ and $\mathrm{T} 2$, with ribs 1 and 2 on the righ. arising both from this hemivertebra and $\mathrm{T} 1$ to $\mathrm{T} 2 \mathrm{Q}$

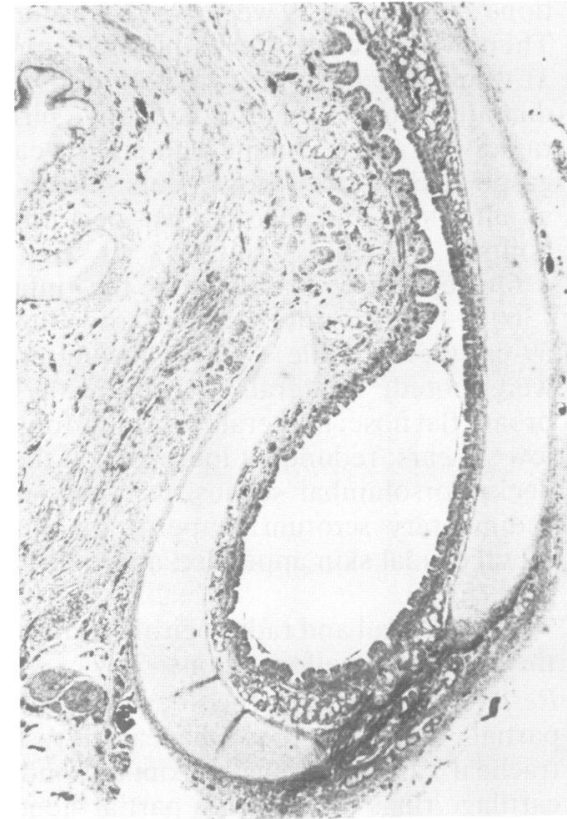

(a)

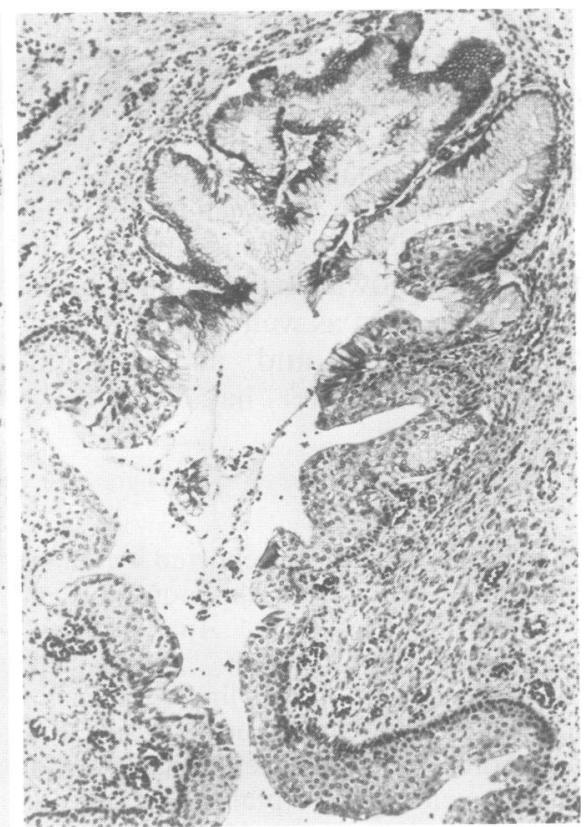

(b)

FIG 2 (a) Partial stenosis of the trachea due to malformed cartilagenous rings (HE). (b)

Heterotopy of columnal intestinal mucosa in the proximal oesophagus, an abnormality observed in sther unrelated conditions $(H E)$.

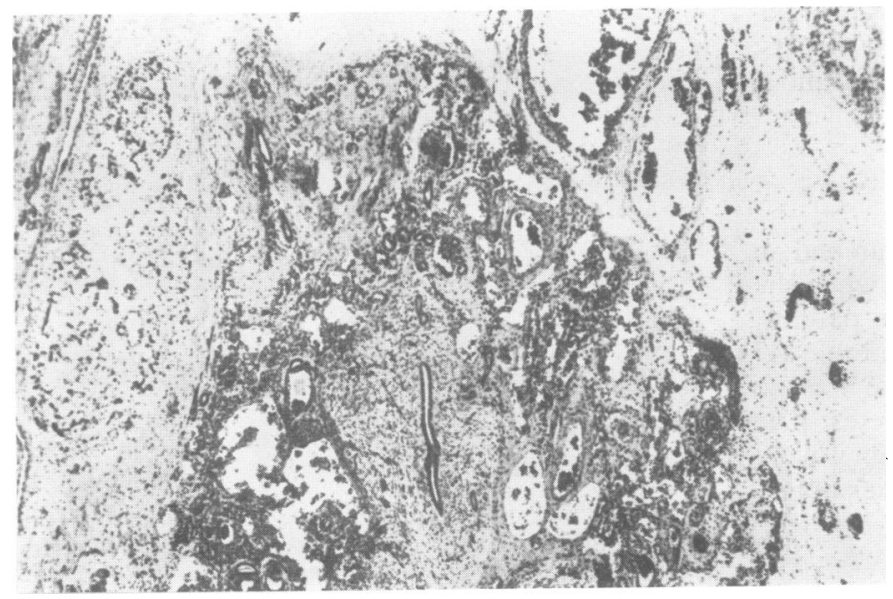

FIG 3 Renal dysplasia with embryonal mesenchyme surrounding tubular structures dilated, cystic tubules, and primitive glomerular structures. No cartilage was observed in either kidney $(H E)$. 

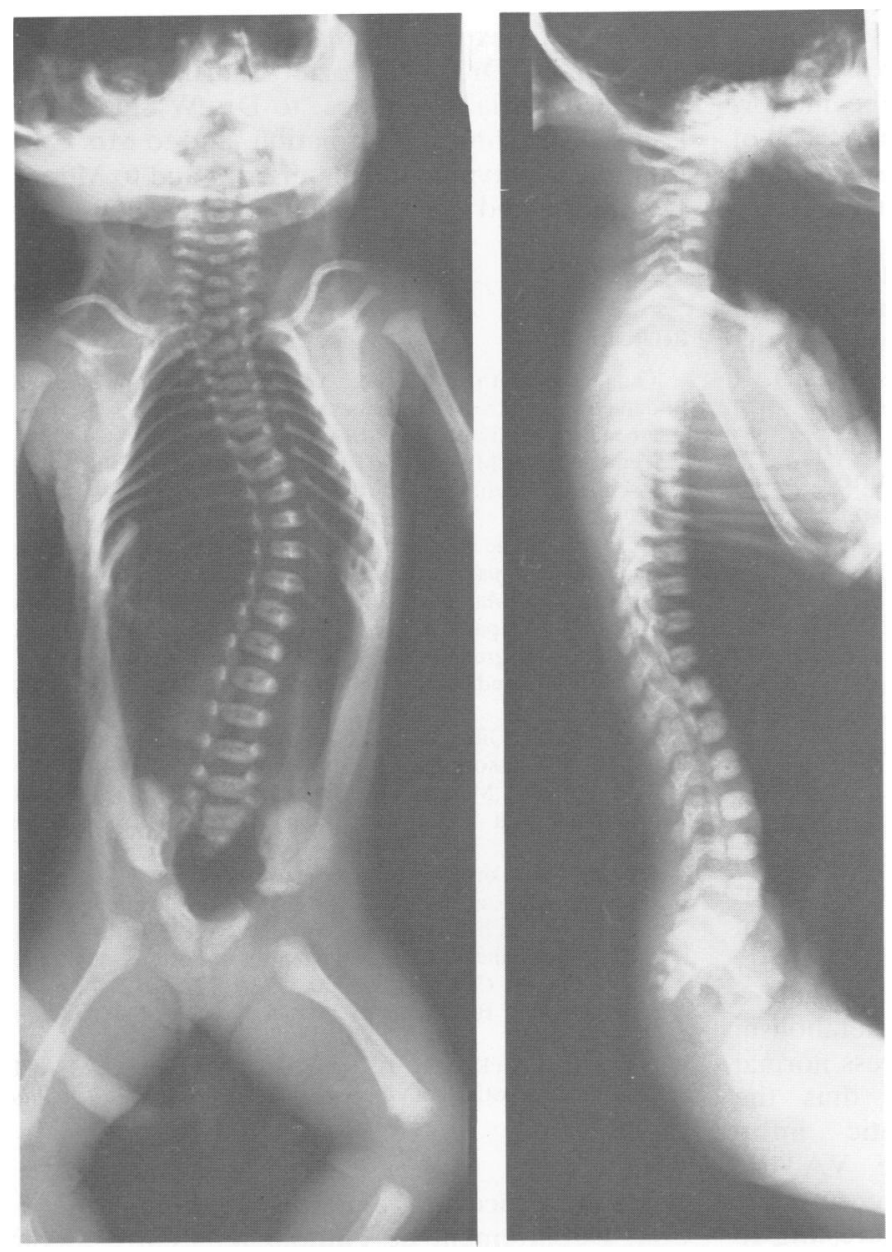

FIG 4 Spinal $x$ rays (see text). Most cases of scoliosis in the VATER association are associated with hemivertebrae. ${ }^{4}$ In this case there is only slight scoliosis in association with the supernumerary vertebra, and the major scoliosis is unrelated to a skeletal malformation.

partial fusion of ribs 3 and 4 on the right; dorsolumbar scoliosis with left convexity; partial fusion of several cervical vertebrae and of the sacrum (fig 4); absence of two toes on the right foot with syndactyly of two others ('lobster claw').

Placenta (290 g): dysmaturity with hyperplastic syncythial trophoblast.

Other: retroperitoneal ectopic adrenal tissue on microscopic examination; wide dysplastic fontanelles.

Chromosomal analysis showed a normal 46, XY G banded karyotype.

\section{Discussion}

The present case of the VATER association had most of the malformations noted in a recent review of 232 patients. ${ }^{4}$ The major defects of the associa- tion were nearly all present (vertebral, anal, tracheo-oesophageal fistula, renal). However, there was no radial dysplasia of the upper limbs, reported in $96 / 217$ cases, or cardiac malformations $(161 / 220$ cases).

The minor common defects were equally well represented (ear anomalies, unusual lobster claw malformation of the lower extremities, genital and gonadal anomalies, scoliosis, rib anomalies, single umbilical artery, ureteral anomalies, cleft lip or palate or both), but there was neither inguinal hernia nor choanal atresia. In extreme cases of the VATER association such as the present one, the differential diagnosis includes trisomy 13 and the CHARGE association (Coloboma, Heart disease, $A$ tresia choanae, Retarded growth and development, Genital anomalies, Ear anomalies). The acrorenal 
mandibular syndrome (ARMS) should also be taken into consideration. ${ }^{5}$ This autosomal recessive condition includes several but not all of the malformations observed in the present case, whereas all of these defects have been described as a non-random association under the VATER acronym in which there is no reported familial incidence.

There were three malformations in the present case which we believe to be previously unreported: agenesis of both the bladder and the penis and the presence of a caudal appendix (rudimentary tail). It is believed that the absent bladder, urethra, and penis are extreme forms of urogenital malformations previously reported in this syndrome. ${ }^{6}$ Most

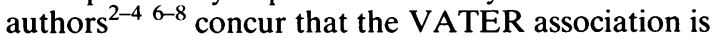
probably the result of an undefined teratogenic influence acting between the fourth and eighth weeks of gestation when the cloacal plate is developing. All the defects of the association are due to imperfect development of mesenchymal elements at this critical period, ${ }^{2}$ as has been convincingly argued by Fitch and Lachance. ${ }^{9}$ A severe disturbance of these events could explain the simultaneous occurrence of agenesis of the anus, bladder, and penis seen in the present case. Parental age does not seem to be implicated ${ }^{2}{ }^{4}$ but several authors have considered a possible role of maternal intake of progesterone and oestrogen during early pregnancy. ${ }^{2} 410$ Others have reported that a transient decrease in cellular oxidative metabolism between days 32 and 39 might cause excess normal cell death during development, and thus the multiple defects observed. ${ }^{11}$ Genetic influences, if present, are weak, for the VATER association has generally been a sporadic occurrence in an otherwise normal family. It is interesting to note that mental development of these patients is generally normal. ${ }^{2}$
We wish to express our gratitude to Professor Engel and to Dr C D Delozier-Blanchet for diagnos tic and editorial assistance, to Drs W Sulzer and Lavi for the clinical information, and to Mrs C L de Marignac for typing the manuscript and to Messrs Denkinger and J C Rumbeli for the photographi work.

\section{References}

1 Quan L, Smith DW. The VATER association: vertebra defects, anal atresia, tracheoesophageal fistula with esophagea atresia, radial dysplasia. Birth Defects 1972;8:75-8.

2 Temtamy SA, Miller JD. Extending the scope of the VATERं association: definition of the VATER syndrome. J Pediat 1974;85:345-9.

3 Denton JR. The association of congenital spinal anomalies witk imperforate anus. Clin Orthop Rel Res 1982;162:91-8.

4 Weaver DD, Mapstone CL, Yu PL. The VATER association? Analysis of 46 patients. Am J Dis Child 1986;140:225-9.

5 Halal F, Desgranges MF, Leduc B, Thêorét G, Bettez Pê Acro-renal-mandibular syndrome. Am J Med Genet 1980;5 277-84.

6 Uehling DT, Gilbert E, Chesney R. Urologic implications of the VATER association. $J$ Urol 1983;129:352-4.

7 Teixeira OHP, Malhotra K, Sellers J, Mercer S. Cardiovascula anomalies with imperforate anus. Arch Dis Child 1983;589 747-9.

${ }^{8}$ Khoury MJ, Cordero JF, Greenberg F, James LM, Erickso® JD. A population study of the VACTERL association: evidenc for its etiologic heterogeneity. Pediatrics 1983;71:815-20.

9 Fitch N, Lachance R. The pathogenesis of Potter's syndrome of renal agenesis. Can Med Assoc J 1972;107:653-6.

10 Kaufman RL. Birth defects and oral contraceptives. Lanc® $1973 ; \mathrm{i}: 1396$.

11 Lloyd DJ, McKenzie J, Kaye HH, Russell G. VATER syndrome: hypothesis and report of two further cases. Teratolog 1976;15:43-6.

Correspondence and requests for reprints to $\mathrm{Dr} J$ Cox, Département de Pathologie, Centre Médicat. Universitaire, 1 rue Michel Servet, $\mathrm{CH}-121 \overline{\underline{x}}$. Geneva 4, Switzerland. 